\title{
Perancangan Sistem Kontrol PID Untuk Pengendali Sumbu Azimuth Turret Pada \\ Turret-gun Kaliber 20mm
}

\author{
Danu Wisnu, Arif Wahjudi, dan Hendro Nurhadi \\ Jurusan Teknik Mesin, Fakultas Teknik Industri, Institut Teknologi Sepuluh Nopember (ITS) \\ Jl. Arief Rahman Hakim, Surabaya 60111 Indonesia \\ e-mail: arif_w@me.its.ac.id
}

\begin{abstract}
Abstrak-Pertahanan negara merupakan segala bentuk daya dan upaya oleh warga negara, dengan tujuan untuk melindungi dan menjaga kedaulatan negara. Salah satu faktor pendukung pertahanan negara di bidang teknologi adalah sistem turret-gun. Dimensi turret-gun disesuaikan dengan kebutuhan penggunaan. Semakin besar kaliber peluru maka semakin besar dimensi dan berat turret-gun, akibatnya turret-gun akan semakin sulit dikendalikan. Oleh karena itu diperlukan perancangan sistem kontrol khususnya kontrol PID yang sesuai. Langkah pertama dalam perancangan sistem kontrol adalah menentukan model matematis dari sistem turret-gun. Berikutnya adalah merancang sistem kontrol yang sesuai dengan menggunakan kontrol PID. Selanjutnya diakhiri dengan pengujian kestabilan dari sistem yang telah dikontrol tersebut. Hasil yang didapat berupa nilai gain proporsional, integral dan derivatif dari metode tuning yang dipakai untuk merancang kontrol PID dari sistem turret-gun. Nilai gain proporsional dan derivatif untuk mendapatkan respon yang memenuhi kriteria perancangan masing-masing sebesar $\mathbf{9 2 5 , 4 7}$ dan 173,83 .
\end{abstract}

Kata Kunci-PID controller, root-locus, sistem kontrol, turret-gun, Ziegler-Nichols

\section{PENDAHULUAN}

$\mathrm{P}$ ERTAHANAN negara pada dasarnya merupakan segala bentuk daya dan upaya oleh seluruh warga negara yang tinggal di negara tersebut, yang bertujuan untuk melindungi dan menjaga kedaulatan negara dari segala bentuk ancaman yang datang baik dari luar maupun dari dalam. Setiap warga negara Indonesia berhak dan wajib untuk ikut serta dalam usaha bela negara, seperti yang tercantum di dalam Undang-Undang Dasar 1945 pasal 30 ayat 1. Sementara itu komponen utama usaha pertahanan dan keamanan negara diatur dalam pasal 30 ayat 2, dimana TNI dan Polri sebagai kekuatan utama, serta rakyat Indonesia sebagai kekuatan pendukung.

Salah satu faktor pendukung usaha pertahanan negara adalah dari segi sarana dan prasarana, seperti teknologi persenjataan maupun kualitas SDM yang mumpuni. Salah satu teknologi persenjataan yang ada yaitu Turret-gun. Turret-gun adalah sistem senapan yang dapat bergerak untuk menembak target dengan pergerakan arah dan sudut yang mengikuti pergerakan target. Turret-gun otomatis karena dikendalikan dari jarak jauh menggunakan remote control, sehingga operator dapat mengoperasikan dengan aman.

Salah satu metode pengendalian yang telah digunakan adalah pengendali PID. Pengendali ini umum digunakan di dalam dunia industri karena sudah diperkenalkan terlebih dahulu. Penelitian terdahulu membandingkan PID dengan metode Accelaration Force Control (AFC) dan Resolve
Motion Control (RAC) [4]. Kemudian selanjutnya dikembangkan dengan menggabungkan RAC dengan AFC yang menggunakan PID [5]. Akan tetapi, penelitian tersebut digunakan pada Remote Control Weapon System (RCWS) kaliber $12,7 \mathrm{~mm}$, sehingga pada penelitian kali ini akan diterapkan pada kaliber 20 milimeter dengan sumbu Azimuth.

\section{PROPORTIONAL, INTEGRAL, DERIVATIVE CONTROLLER}

Kontrol Proportional, Integral, Derivative (PID) adalah sistem pengendali yang umum digunakan di industri maupun militer [1]-[3]. Sekitar 90\% dari peralatan industri menggunakan pengendali PID karena mudah digunakan dan paling sederhana.

Gambar 1 menunjukkan blok diagram kontrol PID yang umum digunakan di industri. Kontrol Proportional (P), Integral (I), dan Derivatif (D) dapat digunakan bersamaan secara paralel ataupun digunakan terpisah dengan tidak menggunakan salah satu komponen P, I atau D.

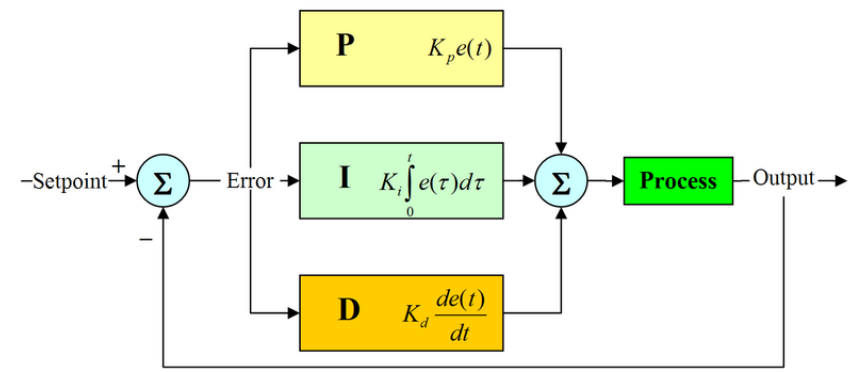

Gambar 1. Blok Diagram kontrol PID

Persamaan nilai keluaran dari kontrol PID, dirumuskan sebagai:

$$
\mathrm{u}(t)=K_{p} e(t)+K_{i} \int_{0}^{t} e(\tau) d \tau+K_{d} \frac{d}{d t} e(t)
$$

Persamaan (1) menjelaskan bahwa nilai keluaran $u(t)$, merupakan jumlah dari gain proportional (Kp), gain integral $(K i)$, dan gain derivative $(K d)$ yang masing-masing dipengaruhi oleh error $(e)$ dalam selang waktu $(t)$ tertentu.

\section{A. Proportional Control}

Kontrol proporsional memiliki output yang sebanding atau proporsional dengan besar sinyal kesalahan (selisih antara nilai yang diinginkan dengan nilai aktualnya, error). Setiap perubahan pada sinyal input menyebabkan sistem langsung mengeluarkan sinyal keluar sebesar konstanta pengalinya. Persamaan kontrol proporsional dirumuskan sebagai [1]: 


$$
u(t)=K_{P} e(t)
$$

$K p$ merupakan gain proportional, $e$ adalah error, dan u merupakan nilai keluaran relatif terhadap waktu $(t)$.

\section{B. Integral Control}

Pengontrol integral berfungsi untuk menghilangkan steady-state error menjadi nol. Jika sebuah plant tidak mempunyai unsur integrator (1/s), pengontrol proposional tidak mampu menjamin output sistem akan tepat sesuai respon yang diinginkan, sehingga dibutuhkan pengontrol integral. Persamaan kontrol integral dirumuskan sebagai [1]:

$$
u(t)=K_{I} \int_{0}^{t} e(t) d t
$$

$K i$ merupakan gain integral, $e$ adalah error, dan $\mathrm{u}$ merupakan nilai keluaran relatif terhadap waktu $(t)$.

\section{Derivative Control}

Besar output dari pengontrol derivatif memiliki sifat seperti operasi diferensial pada umumnya. Pengontrol derivatif menggunakan kecepatan perubahan sinyal kesalahan sebagai parameter pengontrol. Apabila tidak ada perubahan sinyal error, maka output dari kontrol derivatif tidak akan berubah. Persamaan kontrol derivatif dirumuskan sebagai [1]:

$$
u(t)=K_{D} \frac{d}{d t} e(t)
$$

$K d$ merupakan gain derivatif, $e$ adalah error, dan $\mathrm{u}$ merupakan nilai keluaran relatif terhadap waktu $(t)$.

\section{MODEL SISTEM}

Sistem turret-gun dapat dimodelkan berdasarkan persamaan gerak dinamis sebagai berikut [4], [6]:

$$
D(\theta) \ddot{\theta}+C(\theta, \dot{\theta})+G(\theta)=\tau
$$

Parameter $\tau$ adalah torsi, $D(\theta)$ merupakan inersia sistem, $C(\theta, \dot{\theta})$ adalah vektor koriolis dan gaya sentrifugal, dan $G(\theta)$ merupakan gaya gravitasi yang bekerja pada sistem. Gambar 2 merupakan penyederhanaan dari turret-gun.

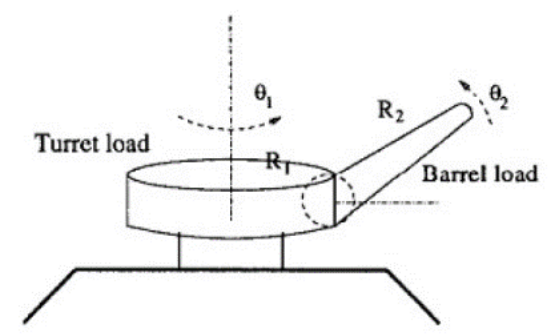

Gambar 2. Sistem turret-gun [4][6]

Rujukan [4] dan [6] menjelaskan hubungan antara torsi yang dibutuhkan sistem gerak sumbu azimuth turret terhadap input berupa posisi sudut turret $\theta_{1}$, kecepatan putar turret $\left(\dot{\theta}_{1}\right)$ dan percepatan sudut turret $\left(\ddot{\theta}_{1}\right)$ serta posisi gun $\left(\theta_{2}\right)$ dan kecepatan putar gun $\left(\dot{\theta}_{2}\right)$ sebagai:

$$
\ddot{\theta}_{1}=\frac{\tau_{1}-C_{11} \dot{\theta}_{1}-C_{12} \dot{\theta}_{2}}{D_{11}}
$$

$$
\begin{aligned}
& D_{11}=\frac{1}{2} m_{1} R_{1}^{2}+m_{2} R_{1}^{2}+m_{2} R_{1} R_{2} \cos \left(\theta_{2}\right) \frac{1}{3} m_{2} R_{2}^{2} \cos ^{2}\left(\theta_{2}\right) \\
& C_{11}=\left(-m_{2} R_{1} R_{2} \sin \left(\theta_{2}\right) \dot{\theta}_{2}\right) \\
& C_{12}=-\frac{1}{3} m_{2} R_{2}^{2} \sin \left(2 \theta_{2}\right) \dot{\theta}_{1}
\end{aligned}
$$

Sistem turret terhubung dengan servomotor DC melalui transmisi yang berfungsi untuk mereduksi putaran yang keluar dari motor. Ilustrasi rangkaian motor, transmisi dan turret ditunjukkan pada gambar 3 .

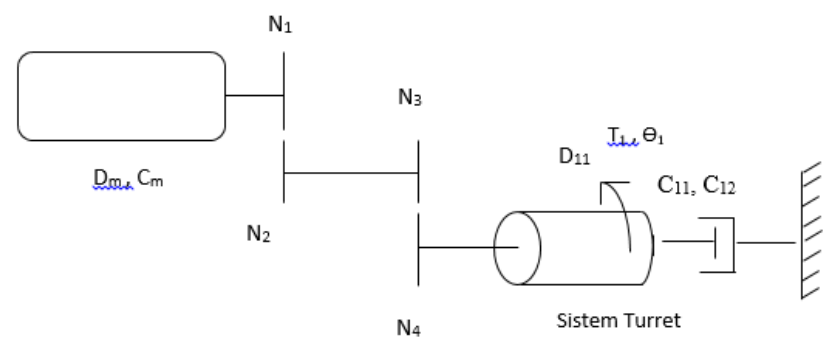

Gambar 3. Ilustrasi rangkaian motor, transmisi dan turret

Sementara itu hubungan antara torsi motor penggerak (Tmotor), transmisi $(N)$ dan torsi dari sistem turret (Tturret) dirumuskan sebagai:

$$
T_{\text {motor }} \times N=T_{\text {turret }}
$$

Rujukan [2] menjelaskan hubungan antara torsi yang dihasilkan motor penggerak dengan tegangan listrik yang diberikan $(E a)$ sebagai:

$$
T_{m}(t)=\frac{K_{t}\left(E_{a}(t)-K_{b} \dot{\theta}_{1}(t)\right)}{R_{a}}
$$

Persamaan (8) menjelaskan hubungan antara parameter konstanta torsi motor $(K t)$, konstanta tegangan $(K b)$ dan armature resistance $(\mathrm{R} a)$ dalam waktu tertentu.

Persamaan (6) dan (8) dimasukkan kedalam persamaan (7), menghasilkan hubungan antara tegangan listrik yang diberikan ke motor terhadap torsi yang diterima oleh sistem sebagai:

$$
\ddot{\theta}_{1}=\frac{K_{t} E_{a} N-\left(N K_{t} K_{b}+R_{a} C_{11}\right) \dot{\theta}_{1}-R_{a} C_{12} \dot{\theta}_{2}}{R_{a} D_{11}}
$$

\section{SIMULASI KONTROL TURRET SUMBU AZIMUTH}

Bab ini menjelaskan metode tuning yang digunakan dan hasil simulasinya. Metode tuning yang digunakan adalah metode root-locus dan metode Ziegler-Nichols. Parameter sistem turret adalah sebagai berikut:

Massa turret, $\mathrm{ml}=1500 \mathrm{~kg}$

Massa gun, $\mathrm{m}_{2}=110 \mathrm{~kg}$

Radius turret, $\mathrm{R}_{1}=0,5 \mathrm{~m}$

Panjang gun, $\mathrm{R}_{2}=2,76 \mathrm{~m}$

Rasio transmisi, $\mathrm{N}=1 / 200$

Voltage constant motor $\mathrm{DC}, \mathrm{K}_{\mathrm{b}}=7,5 \mathrm{~V} / \mathrm{Krpm}$

Torque constant motor $\mathrm{DC}, \mathrm{K}_{\mathrm{t}}=0,072 \mathrm{Nm} / \mathrm{A}$

Armature resistance, $\mathrm{R}_{\mathrm{a}}=0,45 \mathrm{ohm}$

Kriteria perancangan sistem kontrol yang ingin diraih dalam penelitian ini adalah $\%$ overshoot maksimal $20 \%$ dan

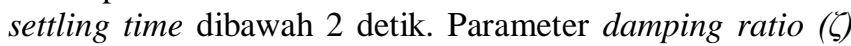
diperoleh sebesar 0,456 . 
Fungsi transfer dari sistem gerak sumbu azimuth yang telah diberikan feedback ditunjukkan pada gambar 4.

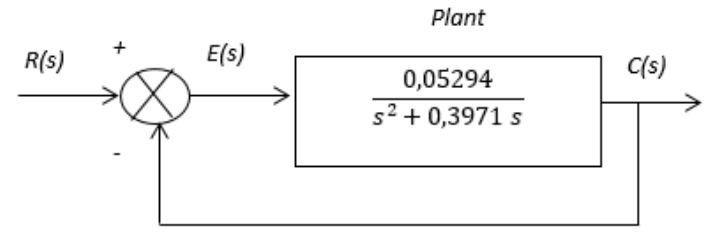

Gambar 4. Blok diagram sistem gerak sumbu azimuth

\section{A. Uncompensated System}

Gambar 5 menunjukkan blok sistem yang belum diberikan kompensator. Input yang diberikan merupakan posisi sudut dari turret.

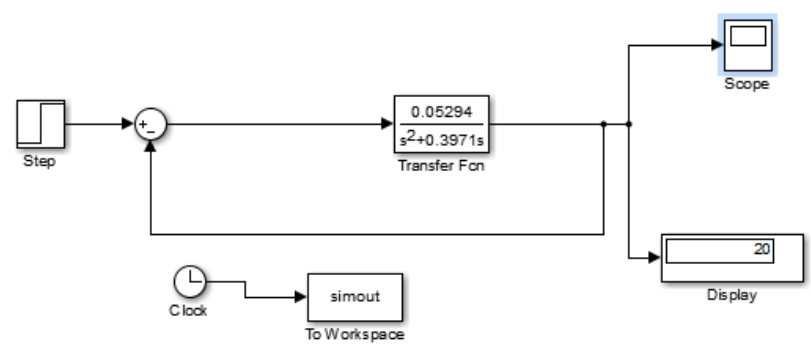

Gambar 5. Blok diagram sistem dengan input 20 derajat

Pengujian awal dilakukan pada input sudut sebesar 20 derajat, dengan hasil seperti pada gambar 6 .

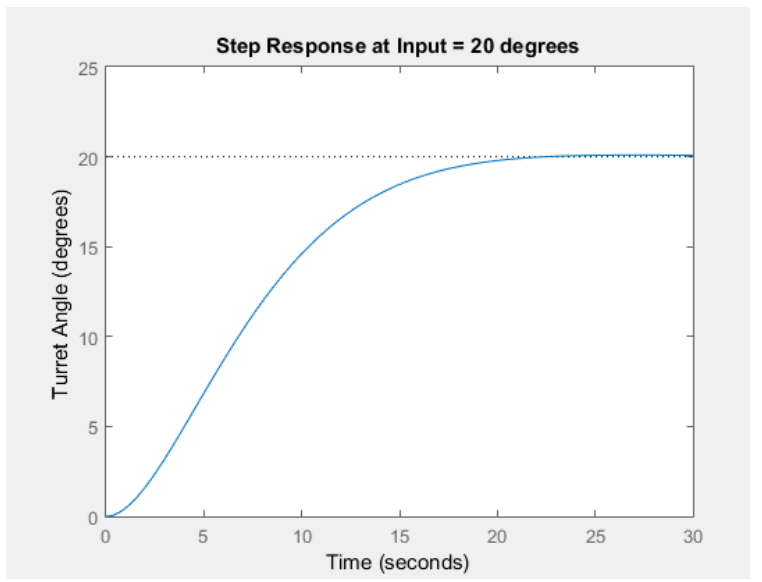

Gambar 6. Grafik respon sistem dengan input 20 derajat

Berdasarkan gambar 6, dapat dilihat bahwa sistem turret tidak memilikin steady-state error namun memiliki settling time diatas 20 detik.

\section{B. Metode Root-locus}

Metode root-locus merupakan metode analisa grafis untuk menentukan besar gain compensator yang diperlukan agar respon sistem dapat memenuhi kriteria perancangan. Root-locus merupakan metode yang memanfaatkan perubahan kedudukan dari setiap akar matematis pada sistem untuk setiap perubahan yang diberikan oleh penguat (gain). Perubahan tersebut lalu diwujudkan dalam sebuah sketsa root-locus. Sketsa root-locus sistem gerak sumbu azimuth ditunjukkan pada gambar 7 .

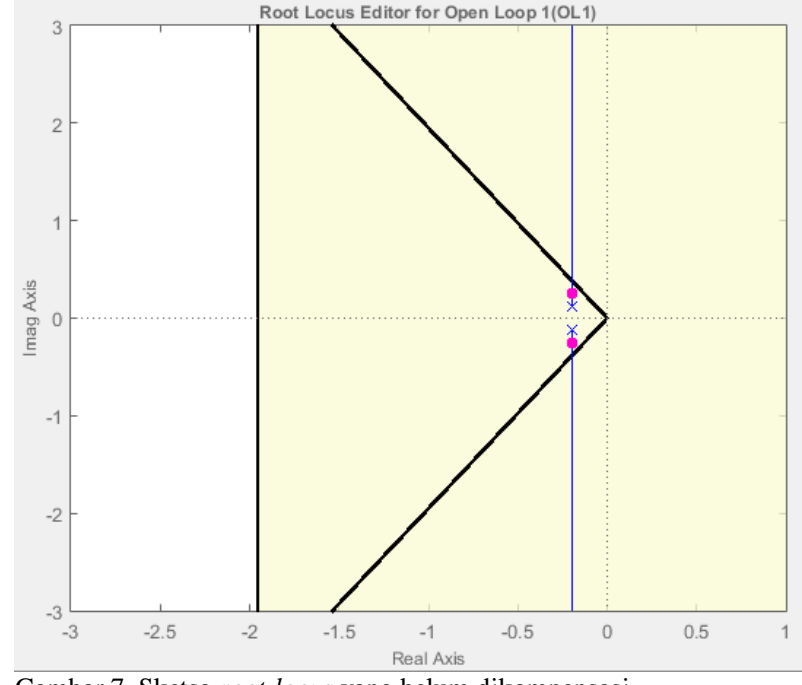

Gambar 7. Sketsa root-locus yang belum dikompensasi.

Sistem ini memiliki pole pada $(-0,1986 \pm 0,1163)$ dan dominant pole pada $(-0,1986 \pm 0,387)$. Dominant pole yang baru diperlukan agar dapat memenuhi kriteria perancangan. Sketsa root-locus dengan dominant pole yang baru pada koordinat $(-2 \pm 3,9035)$ ditunjukkan pada gambar 8 .

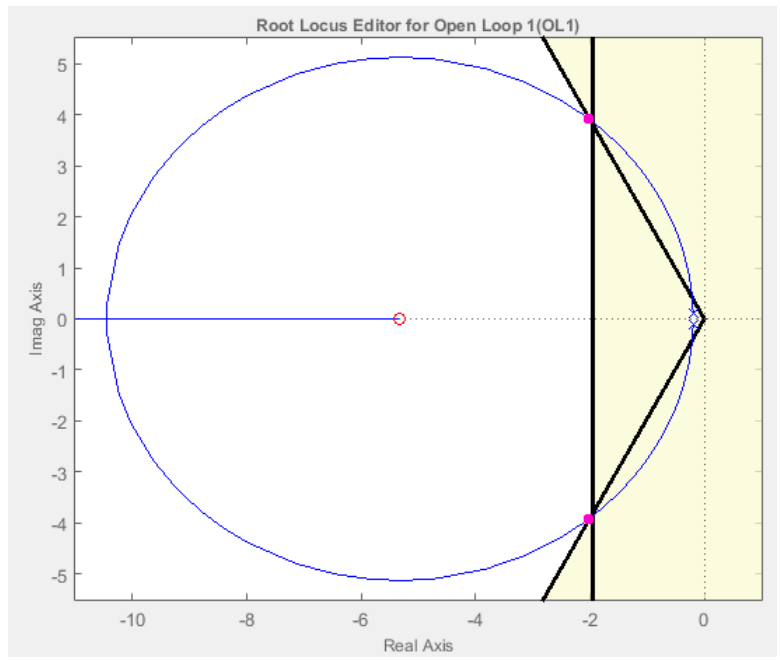

Gambar 8. Sketsa root-locus yang sudah dikompensasi

Dari gambar 8 dapat dilihat bahwa adanya tambahan zero pada koordinat $(-5,324,0)$ menyebabkan perubahan lintasan pole ketika diberikan gain, sehingga mampu mencapai dominant pole yang diinginkan. Grafik respon sistem yang telah diberikan gain compensator sebanyak 68,67 ditunjukkan pada gambar 9 .

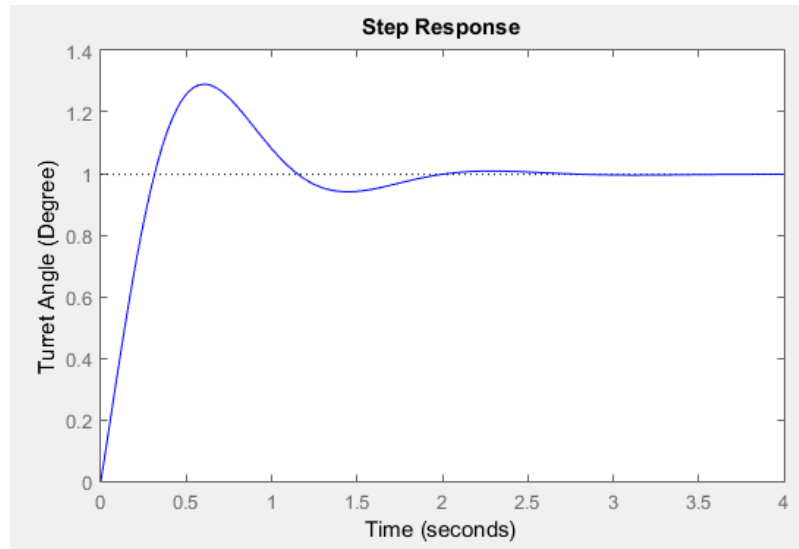

Gambar 9. Grafik respon sistem yang sudah dikompensasi 
Gambar 9 menunjukkan grafik respon sistem memiliki \%overshoot sebesar 29,9, dengan settling time selama 1,84 detik.

Tabel 1 merupakan perbandingan parameter antara sistem yang belum dikompensasi dengan sistem yang telah diberikan gain compensator.

Tabel 1

Respon sistem azimuth turret-gun metode root-locus

\begin{tabular}{ccc}
\hline \hline & Uncompensated & PD Compensated \\
\hline Plant and & $K$ & $K(s+5,324)$ \\
\cline { 2 - 3 } Compensator & $s^{2}+0,3971 s+0,05294$ & $s^{2}+0,3971 s+0,05294$ \\
Dominant Poles & $-0,199 \pm j 0,387$ & $-2 \pm j 3,9035$ \\
$K$ & 0,05294 & 68,67 \\
$\zeta^{*}$ & 0,863 & 0,456 \\
$\omega_{n}{ }^{*}$ & 0,23 & 4,386 \\
Ts & 0 & $29,9 \%$ \\
Tp & 1,74 \\
Zero & 18,7 & 0,571 \\
Steady-State & 11,8 & $-5,324$ \\
Error $(\%)$ & - & 0 \\
$* \omega_{\mathrm{n}}-$ Frekuensi natural & \\
$*$ Ts - Settling time & 0 & \\
$*$ Tp - Peak time & & \\
$* \zeta \quad-$ Damping ratio &
\end{tabular}

Grafik pada gambar 9 masih menunjukkan \%overshoot yang masih diatas kriteria perancangan. Apabila gain compensator diperbesar menjadi 173,83, grafik respon akan menunjukkan hasil seperti pada gambar 10 .

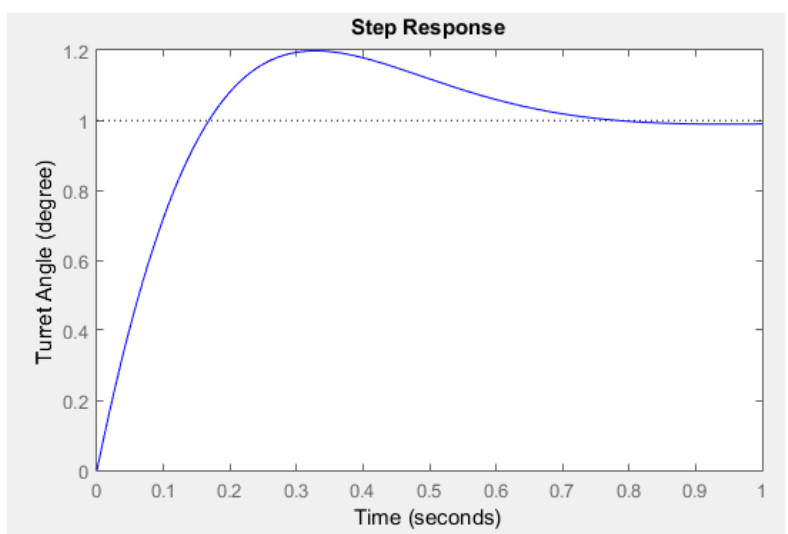

Gambar 10. Grafik respon dengan gain compensator 173,83

Perbesaran gain compensator menjadi 173,83 menyebabkan grafik respon menunjukkan \%overshoot sebesar 19,9\% dan settling time selama 0,697 detik. Nilai gain proportional $\mathrm{Kp}$ dan gain derivatif diperoleh sebesar masing-masing 925,47 dan 173,83.

\section{Metode Ziegler-Nichols}

Metode tuning Ziegler-Nichols merupakan salah satu metode perhitungan untuk mencari nilai gain $K p, K i$ dan $K d$ berdasarkan grafik awal respon sistem [1]. Nilai $K i$ dan $K d$ dapat ditentukan setelah nilai time integral (Ti) dan time derivative (Td) diketahui dari perumusan pada tabel 2 . Tabel 2

Aturan tuning Ziegler-Nichols berdasarkan Delay Time dan Time

\begin{tabular}{cccc}
\multicolumn{5}{c}{ Constant [1] } \\
\hline \hline Jenis Kontroler & $K p$ & $T i$ & $T d$ \\
\hline P & $\frac{T}{L}$ & $e$ & 0 \\
PI & $0,9 \frac{T}{L}$ & $\frac{L}{0,3}$ & 0 \\
\hline
\end{tabular}

\begin{tabular}{llll} 
PID & $1,2 \frac{T}{L}$ & $2 L$ & $0,5 L$ \\
\hline
\end{tabular}

Nilai $T i$ dan $T d$ selanjutnya dimasukkan kedalam persamaan 10 yang merupakan persamaan gain compensator dari metode tuning Ziegler-Nichols:

$$
G_{c}(s)=K_{p}\left(1+\frac{1}{T_{i} s}+T_{d} s\right)
$$

Selanjutnya blok diagram sistem yang baru dapat dibentuk seperti pada gambar 11 .

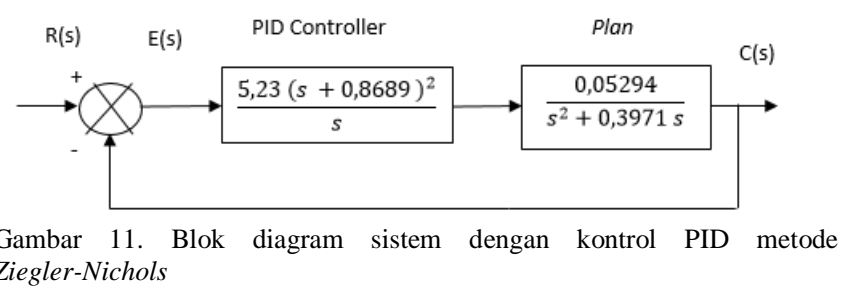

Grafik respon sistem yang telah ditambahkan kontrol PID dengan metode tuning Ziegler-Nichols ditunjukkan pada gambar 12 .

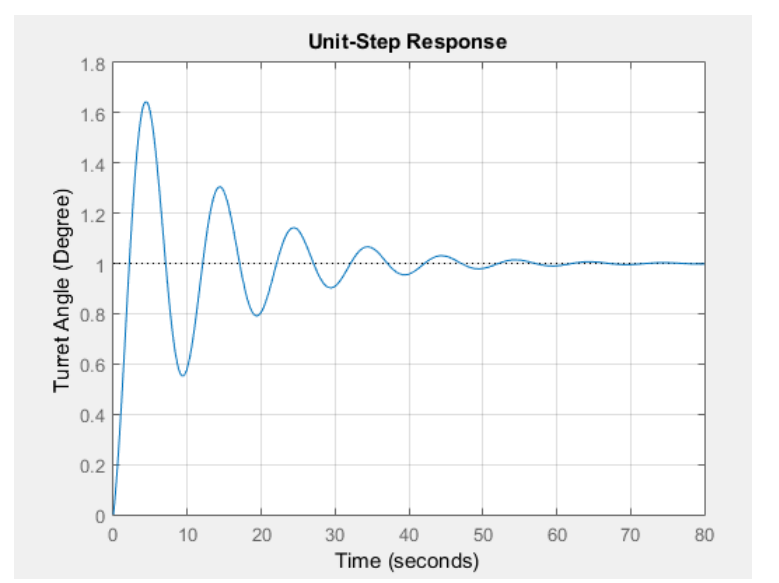

Gambar 12. Grafik respon sistem dengan kontrol PID tuning Ziegler-Nichols

Tabel 3 merupakan perbandingan parameter antara sistem yang belum dikompensasi dengan sistem yang telah diberikan kontrol PID.

Tabel 3

Respon sistem azimuth turret-gun metode tuning Ziegler-Nichols

\begin{tabular}{ccc}
\hline \hline & Uncompensated & PID \\
Compensated \\
\hline$K p$ & 1 & 12,03 \\
$K i$ & 0 & 5,23 \\
$K d$ & 0 & 20,92 \\
$\zeta$ & 0,863 & 0,138 \\
$\omega n$ & 0,23 & 0,579 \\
$\% O S$ & 0 & $64,5 \%$ \\
$T s$ & 18,7 & 49,9 \\
$T p$ & 11,8 & 4,42 \\
Steady state & 0 & 0 \\
Error $(\%)$ & & \\
\hline \hline
\end{tabular}

\section{KESIMPULAN DAN SARAN}

Berdasarkan grafik respon yang diperoleh dari gambar 9 dan 11, terdapat perbedaan yang signifikan antara hasil tuning dari kedua metode. Metode root-locus menghasilkan respon sistem yang memiliki settling time 1,74 detik, namun masih memiliki \%overshoot diatas 20\%. Sementara itu metode Ziegler-Nichols menghasilkan respon sistem dengan 
$\%$ overshoot $64,5 \%$ dan settling time 49,9 detik. Kedua metode sama-sama tidak memiliki steady-state error.

Hasil yang memenuhi kriteria perancangan diperoleh dengan menggunakan metode root-locus. Gain compensator K diperbesar hingga 173,83 dan diperoleh data berupa grafik respon yang memiliki \% overshoot $19,9 \%$ dan settling time 0,697 detik

\section{DAFTAR PUSTAKA}

[1] Ogata, K., "Modern Control Engineering", $5^{\text {th }}$ Edition, Prentice Hall, New Jersey (2010)

[2] Nise, Norman S., "Control System Engineering", 6 $6^{\text {th }}$ Edition, John Wiley \& Sons. Inc (2011),

[3] Johnson, Michael A. dan Moradi, M.H., "PID Control: New Identification and Design Methods", Springer, London (2005).

[4] Nasyir, M. T., Nurhadi, H., Pramujati, B., dan Pitowarno, E.’Design and Realization of an Automatic Turret Gun", IES (2014).

[5] Nasyir, M. T., "Aplikasi Active Force Control pada Turret-gun pada Kendaraan Tempur Darat”, Jurusan Teknik Mesin FTI-ITS, Surabaya (2014).

[6] Musonnifah, S., "Resolve Acceleration Control (RAC) dan Active Force Control (AFC) pada Sistem Turret-gun Kaliber 20 Milimeter", Jurusan Matematika FMIPA-ITS, Surabaya (2016). 